\title{
Arrow of time: Metaphorical construals of entropy and the second law of thermodynamics
}

\author{
Tamer Amin, Fredrik Jeppsson, Jesper Haglund and Helge Strömdahl
}

\section{Linköping University Post Print}

N.B.: When citing this work, cite the original article.

This is the authors' version of the following article:

Tamer Amin, Fredrik Jeppsson, Jesper Haglund and Helge Strömdahl, Arrow of time: Metaphorical construals of entropy and the second law of thermodynamics, 2012, Science Education, (5), 96, 818-848.

which has been published in final form at:

http://dx.doi.org/10.1002/sce.21015

Copyright: Wiley-Blackwell

http://eu.wiley.com/WileyCDA/Brand/id-35.html

Postprint available at: Linköping University Electronic Press

http://urn.kb.se/resolve?urn=urn:nbn:se:liu:diva-79912 


\section{COVERSHEET}

The Arrow of Time:

Metaphorical Construals of Entropy and the Second Law of Thermodynamics

Tamer G. Amin ${ }^{*}$, Fredrik Jeppsson ${ }^{\#}$, Jesper Haglund ${ }^{\#}$

and Helge Strömdahl ${ }^{\#}$

* Department of Education

Lebanese American University

PO Box 13-5053 Chouran

Beirut 1102 2801, Lebanon
\# The Swedish National Graduate School in

Science and Technology Education

Linköping University, S-60174,

Norrköping, Sweden

Corresponding author, e-mail tamer.amin@lau.edu.lb and telephone +961 70945931 


\title{
The Arrow of Time:
}

\section{Metaphorical Construals of Entropy and the Second Law of Thermodynamics}

\begin{abstract}
Various features of scientific discourse have been characterized in the science education literature and challenges students face in appropriating these features have been explored. Using the framework of conceptual metaphor, this paper sought to identify explicit and implicit metaphors in pedagogical texts dealing with the concept of entropy and the second law of thermodynamics, an abstract and challenging domain for learners. Three university level textbooks were analyzed from a conceptual metaphor perspective and a range of explicit and implicit metaphors identified. Explicit metaphors identified include Entropy As Disorder, Thermodynamics Processes As Movements Along A Path, and Energetic Exchange As Financial Transactions among others. Implicit metaphors include application and elaboration of the generic Location Event Structure metaphor, application of the Object Event Structure metaphor, and others. The similarities and differences between explicit and implicit metaphors found in the textbooks are also described. Two key pedagogical implications are discussed: that the selection of explicit instructional metaphors can be guided by consistency with implicit metaphors; and that the range of implicit metaphors found in pedagogical texts imply that a multiple instructional metaphor strategy is warranted. The depth of the phenomenon of conceptual metaphor and its implications for future research are also discussed.
\end{abstract}




\section{Introduction}

The appropriation of scientific discourse has been acknowledged as an important goal of science education that is challenging for many learners (Duschl \& Osborne, 2002; Duschl, Schweingruber \& Shouse, 2007; Halliday \& Martin, 1993; Lemke, 1990; Yerrick \& Roth, 2005). A strategy that researchers have adopted to address this challenge has been to characterize the discourse, document the difficulties that learners face and identify features of learning environments that support appropriation. Various aspects of scientific discourse have been considered in this work - for example, the coordination of theory and evidence via argumentation (Duschl \& Osborne, 2002), the construction of scientifically acceptable thematic relationships (e.g. taxonomic) between ideas (Lemke, 1990) and the static, synoptic construal of natural processes through nominalization (Halliday \& Martin, 1993). In this paper, we focus on the construal of abstract scientific concepts in terms of concrete conceptual schemas via metaphor. For over three decades now, research in cognitive linguistics has been documenting patterns of metaphorical language use in everyday discourse that reflect underlying mappings between conceptual domains referred to as conceptual metaphor (Lakoff \& Johnson, 1980, 1999). Such patterns are being identified in scientific and mathematical discourse as well (AlZahrani, 2008; Amin, 2009; Brookes \& Etkina, 2007; Fernandez-Duque \& Johnson, 2002; Lakoff \& Núñez, 2000).

There are various reasons to believe that appropriating the metaphorical mappings implicit in scientific discourse might be important in learning science: (1) analogical mapping between conceptual domains is widely thought to be a key process in knowledge construction, both in scientists (e.g. Clement, 2009; Hesse, 1966; Nersessian, 2008) and learners (e.g. Carey, 2009; Gentner \& Wolff, 2000; Vosniadou \& Ortony, 1989); (2) the explicit use of metaphor and 
analogy in science instruction has been found to be an effective teaching strategy but can lead students to misunderstand concepts when not used carefully (e.g Aubusson, Harrison, \& Ritchie, 2006; Dagher, 1994; Duit, 1991); and (3) research has begun to suggest that learners misinterpret implicit metaphors used in scientific language leading to misconceptions (Brookes \& Etkina, 2007).

In this paper, we characterize metaphors used explicitly and implicitly in university level educational texts dealing with the particularly abstract concept of entropy and the second law of thermodynamics. We also analyze the similarities and differences between the sets of explicit and implicit metaphors identified. Given the extensive discussion in the literature of the explicit use of metaphor and analogy in the teaching and learning of scientific concepts, we seek to draw particular attention to the pervasive and systematic use of a range of implicit conceptual metaphors in pedagogical texts. We suggest that consistency with patterns of implicit metaphors can be used as a criterion for evaluating explicit instructional metaphors proposed as candidates for teaching in some domain. Moreover, we argue that the variety of implicit conceptual metaphors found in pedagogical texts suggests the need for an instructional strategy involving use of multiple analogies, as previously proposed in the literature (Aubusson et al., 2006; Spiro, Feltovitch, Coulson \& Anderson, 1989). We conclude with a discussion of the depth of the phenomenon of metaphor in science and science teaching and learning, raising the need for further research in this area (see also Amin, 2009; Brookes \& Etkina, 2007). In the rest of this introduction, we situate this study with respect to research on the role of metaphor and analogy in knowledge construction and learning, in general, and in relation to previous research on the teaching and learning of the concept of entropy and the second law of thermodynamics.

\section{Metaphor, Analogy and Language in Science, Learning and Instruction}


Research on metaphor and analogy in scientific knowledge construction, conceptual development, science learning and instruction is extensive. An exhaustive review is clearly beyond the scope of this paper. In this section, we situate the present study, clarifying its focus and our use of terminology.

The terms "metaphor" and "analogy" have been used in a variety of different ways, sometimes collapsed and frequently distinguished, but in different ways (Aubusson et al., 2006; Clement, 2009; Dagher, 1994; Duit, 1991; Gentner \& Jeziorski, 1993; Hesse, 1966; Lakoff \& Johnson, 1980, 1999; Nersessian, 2008). All researchers use both terms to refer in some way to the construal of an idea in terms of another - we refer to a "blanket of cloud;" liken an atom to a solar system; and think of the natural, goalless process of the evolution of organisms as natural selection. In this investigation, we adopt Gentner and Jeziorski's (1993) distinction between metaphor, as a general term that captures all cases of understanding one thing in terms of another, and analogy, as a more specific term reserved for cases in which relations from one domain are mapped onto another (e.g. spatial and dynamic relations between nucleus and electrons in an atom mapped onto those between a sun and planets in a solar system). Metaphors that involve attribute-based similarities as in "she has a moon face" (referring to similarity in circular shape) or "he has a lion's heart" (referring to similarity in the attribute of courage) would not qualify as analogies.

Another clarifying distinction is between theory constitutive and pedagogical (or exegetic) metaphors (Boyd, 1979/1993). That metaphors can be used for instructional purposes to facilitate the understanding of a difficult concept by appealing to a concept more familiar to a learner is uncontroversial. Moreover, many observers have noted the use of metaphors in the language of scientists. This use of metaphor is often dismissed as either helpful for 
communicating new ideas or as serving a heuristic function in supporting the generation of new theories, but not constitutive of scientific theories. The view that metaphors in science can be constitutive of theories has gained adherents among philosophers of science, especially those supporting a model-based view of scientific theories (Hesse, 1966; Giere, 1988; Nersessian, 2008). This warrants maintaining the distinction between theory constitutive and pedagogical metaphors. In Gentner \& Jeziorski’s (1993) terms, most (current) scientific theory constitutive metaphors are analogies because they involve systematic relational mappings, although they suggest that theory constitutive metaphors that involve attributed-based similarities were more prevalent earlier in the history of science.

This study focuses on the pedagogical use of metaphor. Use of pedagogical metaphors (including analogies) has been widely researched and discussed (see Aubusson et al., 2006; Dagher, 1994; and Duit, 1991 for reviews). Interest in pedagogical use of metaphors has been motivated in part by the identification of cross-domain mapping as a source of creativity in scientific knowledge construction (Clement, 2009, Nersessian, 2008) and the importance of models in science (Hesse, 1966; Giere, 1988). Research on concept development and learning has also documented the power and centrality of the process of analogical mapping in the emergence of novel concepts over the course of development without reliance on formal instruction (e.g. Carey, 1999, 2009; Gentner \& Wolff, 2000; Vosniadou \& Ortony, 1989). Research in science education has made use of these foundational lines of research and has investigated diverse approaches to the use of analogies in science instruction (Aubusson et al., 2006; Dagher, 1994; Duit, 1991). Among the key results of this research has been the recognition that it is important to give explicit attention during instruction to the limitations of particular analogies and where they break down. Moreover, there is an emerging consensus among 
researchers that using multiple, complementary analogies into instruction is a powerful instructional strategy that helps address the unintended inferences that can be generated from any one analogy alone (Aubusson et al., 2006; Duit, 1991; Sprio et al., 1989).

The ideas reviewed thus far have not made reference to the fact that the term "metaphor" is often used to refer to a linguistic phenomenon. Indeed, it is not uncommon for analogy to be distinguished from metaphor by noting that the latter is a linguistic phenomenon whereas the former is more deeply cognitive. As noted above, we prefer to distinguish between metaphor and analogy on cognitive grounds, treating metaphor as a more general cognitive phenomenon, encompassing both attribute-based similarity comparisons and mapping relations, reserving the term "analogy" for the latter only. However, we acknowledge that language is frequently implicated in the general cognitive phenomenon of metaphor (in our more general use of the term). Indeed, we believe that interest in the role of metaphor in learning in science education research has often not paid sufficient attention to its close connection with language.

Our view of metaphor as a cognitive phenomenon that is also pervasively tied to language use is based on developments in the field of cognitive linguistics over the last three decades, in particular, research on conceptual metaphor (Lakoff \& Johnson, 1980, 1999; Reddy, 1979). This work has shown that close examination of everyday language reveals extended patterns in metaphorical language use reflecting underlying conceptual mappings between concrete source domains and abstract target domains. For example, Lakoff and Johnson (1980) argued that sentences like 'Your claims are indefensible,' 'He attacked every weak point in my argument,' and 'If you use that [reasoning] strategy, he'll wipe you out' (and many other examples) seem to reflect a systematic pattern of conceptual mappings where an understanding of argument is structured in terms of our understanding of physical conflict. They called this the 
Argument Is War conceptual metaphor. Gentner \& Jeziorski (1993) note that as systematic mappings of relations between distinct conceptual domains conceptual metaphors should be considered analogies.

Lakoff and Johnson (1999) have gone on to argue that basic concepts such as time, cause, change, state, and purpose are themselves understood metaphorically in terms of imageschematic structures understood as abstractions from sensorimotor experience. Illustrating the degree of systematicity and the subtle shifts in perspective involved in conceptual mapping underlying commonplace language use, they identified two different ways in which events are metaphorically construed. One of these they called the Location Event Structure metaphor. In this conceptual metaphor states are construed as locations (e.g. 'I'm in love'), changes are construed as movements into or out of locations (e.g. 'I got out of my depression'), and caused changes are construed as forced movements (e.g. 'The tragedy pushed me into a deep sadness'). The other conceptual metaphor for understanding events they called the Object Event Structure metaphor. In this case, attributes or states are construed as possessions (e.g., 'He has a lively spirit'), changes of state or attribute are construed as movement of possessions (e.g. 'He got a cold'), and caused changes of state are construed as forced transfer of a possession (e.g. 'The music gave me a headache'). While this is quite similar to the Location Event Structure metaphor it involves a figure-ground reversal. In the Location Event Structure metaphor, the state was construed as the location, with the entity the state of which is being characterized construed as moving with respect to these locations. In the Object Event Structure metaphor, on the other hand, states or attributes are the thing being exchanged with the entity characterized construed as a location or container. Moreover, Talmy $(1988,2000)$ has identified extensive patterns of "force dynamics" through which language expresses the interaction of entities with respect to notions of 
force such as letting, blocking, resistance, sustained force and others. Talmy's analysis identifies literal language use dealing with actual physical interactions (e.g. 'Opening the tap let the water run;' 'The animals were released into the wild'). In addition, he identifies metaphorical extensions of force dynamic construals to psychological and social phenomena (e.g. 'With the onset of summer I felt released;' 'Getting a babysitter let us have the night off').

It should be noted that many of the instances of metaphorical language use identified by conceptual metaphor researchers are often highly conventional instances of language use. They are implicit in language use and are often not recognized as metaphorical. Thus, they might be assumed to be "dead metaphors," expressions surviving in the language but not invoking any concrete source domain when used. The assumption of conceptual metaphor research is that underlying conceptual mappings are at work.

One reason to believe that this latter assumption might be correct is that Lakoff and Turner (1989) found that a large collection of proverbs and novel poetic metaphors could be understood as reflecting elaborations of systematic mappings between generic conceptual domains. For example, the personification of death, as in The Grim Reaper, reflects the metaphorical conceptualization of time as an object moving towards you as seen in highly conventional expressions like 'The due date is approaching;' and 'Christmas is almost here'). A variety of other sources of evidence are appealed to in addition to the consistency between creative poetic metaphors and underlying conceptual metaphors: the systematic nature of metaphorical language use; the inferences readily generated; the nature of gestures accompanying language use; and empirical psycholinguistic research (see Gibbs, 1994, 2005 for reviews). 
The conceptual metaphor perspective has also been applied to technical scientific domains including the theory of natural selection (e.g. Al-Zahrani, 2008); the scientific concept of energy (Amin, 2009); quantum mechanics and thermodynamics (Brookes, 2006; Brookes \& Etkina, 2007); cognitive theories of attention (Fernandez-Duque \& Johnson, 1999, 2002); and scientific problem-solving using the concept of entropy (Jeppsson, Haglund, Amin \& Strömdahl, submitted); as well as a range of mathematical concepts (Lakoff \& Núñez, 1997, 2000). The pervasiveness of implicit conceptual metaphors in technical language is interesting to consider in light of the advantages and challenges of using metaphor in science learning discussed in the science education literature. Brookes and Etkina (2007) have already documented problems students face with metaphorical scientific language in the domain of quantum mechanics. They note patterns of misconceptions among students that reflect overly literal interpretations of concrete language used in this domain such as "barriers," and "wells." Moreover, Amin (2009) has suggested that some of the early misunderstandings of the concept of energy seem to derive from conceptual metaphors underlying everyday language involving the word "energy." He hypothesizes that the use of conceptual metaphors in everyday and scientific use of the word “energy" might be seen as making a positive contribution to learning in the scientific concept, but can present challenges as well. More research is needed that characterizes the use of implicit conceptual metaphor in the scientific language to which learners are exposed, that documents their roles in the learning process and in turn, can serve as a basis for the design of learning environments that support effective appropriation of the use of these metaphors. The present study seeks to characterize conceptual metaphors implicit in pedagogical language dealing with the concept of entropy and the second law of thermodynamics. 


\section{The Concept of Entropy and the Second Law of Thermodynamics: The Challenges of Teaching and Learning}

The concept of entropy and the second law of thermodynamics are used to describe the direction of spontaneous processes. An example of a spontaneous, irreversible process is when a weight hits the floor after a fall from some height. In this example, the potential energy of the weight at the initial high position gradually transforms into kinetic energy, as the weight moves with increasing velocity. At the point of impact, the kinetic energy is dispersed in the weight and the surroundings in the process of heating, which makes the energy less available for doing work than in the initial state. The second law of thermodynamics states that this process of heating cannot spontaneously occur in the reverse direction. The introduction of the concept of entropy is a way to operationalize the second law of thermodynamics, since spontaneous, irreversible processes are always accompanied by an increase of entropy in the system and its surroundings. In contrast to irreversible processes, a reversible process can be driven in the opposite direction without dispersal of energy, and hence the entropy is constant. Introducing a quantity called entropy that increases when, for example, a weight hits the floor and energy is dispersed is a macroscopic perspective that does not tell us how and why the entropy increases. Statistical mechanics, focusing on microscopic properties, may offer a more fundamental understanding. In statistical mechanics, the equation $S=k_{B} \ln \Omega$ states that the entropy $S$ is proportional to the natural logarithm of the number of microstates of a system, $\Omega$, i.e. the number of microscopic states of the system. Eventually, the macroscopic and microscopic perspectives have to be related to each other for an in-depth understanding of entropy. In short, entropy is characterized as: being a state function, depending on the state of the system but not the path of reaching the 
state; being an extensive quantity, proportional to the system size, but not conserved; increasing for irreversible processes but constant for reversible processes.

There is a debate in the science education literature on teaching the second law of thermodynamics dealing with the broad question of whether a macroscopic or a microscopic approach should be the entry point for instruction (Baierlein, 1994; Kautz, Heron, Shaffer \& McDermott, 2005; Reif, 1999). Kautz et al. (2005) claim that thermodynamic concepts have to be firmly understood in macroscopic contexts first, using for example bicycle pumps, before microscopic models are introduced. Reif (1999) argues for the opposite view, favoring a microscopic, atomistic approach and emphasizing the need to understand the underlying mechanisms of physical phenomena. He claims that the macroscopic level is difficult to understand because the concepts are not easy to visualize. Regardless of this debate, most university presentations of this topic address both levels of description at some point and the coordination between them. The texts analyzed in this study all cover these three aspects.

Empirical studies in science education have identified the concept of entropy and the second law of thermodynamics as challenging for learners (e.g. Brosseau \& Viard, 1992; Christensen, Melzer, \& Ogilvie, 2009; Cochran \& Heron, 2006). Christensen, Meltzer and Ogilvie (2009) performed an extensive study on students' conceptions of entropy and the second law of thermodynamics. Their main finding was that the idea that the entropy of a system and its surrounding is conserved in spontaneous processes is one of the most common misunderstandings among students. These ideas may be due to confusion between entropy and energy, another extensive quantity which is conserved. The belief that entropy is conserved leads to difficulties in understanding the role of entropy in the second law of thermodynamics and thermodynamic processes. 
In science teaching, the metaphor Entropy is Disorder has been used frequently, but has received criticism (e.g. Lambert, 2002). Brosseau and Viard (1992) conducted an interview study among university physics students examining the conceptual understanding of entropy. They found that only one out of ten students grasped the idea that entropy is constant during adiabatic (no heat exchanged) reversible expansion of an ideal gas. Seven of the others argued that as the volume increases, so does the 'disorder' and, hence, the entropy. By applying the disorder metaphor in this way, the students incorporate only the contribution of spatial configuration to the entropy and fail to acknowledge the energy contribution. Brosseau and Viard suggest that the disorder metaphor has to be balanced by other explanatory ideas for an adequate understanding of entropy.

There is an ongoing discussion in science education research about the adequacy of different metaphors and analogies used as deliberate pedagogical tools for explaining and introducing the concept of entropy (e.g. Brissaud, 2005; Falk, Herrmann, \& Schmid, 1983; Lambert, 2002; Leff, 1996, 2007; Styer, 2000). Authors have proposed a variety of instructional metaphors and have debated their relative merits. In addition to disorder, researchers and educators have suggested the notions of freedom, spreading, information, substance and monetary value as potentially valuable source domains in instructional metaphors in this domain. We return to this issue in the discussion section of this paper in light of the implicit metaphors identified in the texts analyzed.

This study extends earlier attempts to characterize features of scientific discourse in the domain of thermodynamics drawing on the framework of conceptual metaphor and other constructs from cognitive linguistics (Amin, 2009; Brookes, 2006; Haglund, Jeppsson and Strömdahl, 2010; Jeppsson, Haglund and Strömdahl, 2011). Amin (2009) presents a conceptual 
metaphor analysis of the lay and scientific use of the term "energy." His claims about the scientific use of the term were based on analyzing The Feynman Lectures on Physics (Feynman, Leighton, \& Sands, 1963). The scientific concept of energy was found to be construed metaphorically in terms of concrete source domains such as schemas of containment, possession, movement along a path, force dynamics and part-whole. Amin's (2009) study was limited to three of the aspects of energy: transport, transformation and conservation, and relied only on the analysis of sentences including the term "energy." The study reported here extends that work to considering a fourth aspect of the concept of energy, namely, degradation.

Drawing from a cognitive linguistic account of polysemy, Haglund, et al. (2010) recently identified the multiple senses of the term entropy. They followed Evans's (2005) view that meanings of a word represent subjective, contextual interpretations, whereas senses of a word correspond to more stable, shared interpretations, which typically can be found as separate entries in a dictionary. Haglund, et al. claimed that the multiplicity of senses constitutes one of the challenges in the teaching and learning of entropy. In their study, five distinct senses of entropy were identified: the macroscopic thermodynamic sense, as coined by Clausius; the microscopic statistical mechanical sense, introduced by Boltzmann; Shannon's information theory sense; the disorder sense, based on the metaphor entropy is disorder, often used in teaching and non-science contexts; and the homogeneity sense, where entropy is seen as a quality, exclusively used in non-science settings. In addition, Jeppsson et al. (2011) surveyed the range of metaphors for understanding entropy and the second law of thermodynamics discussed in the science education literature. Based on this survey, they advocated a pedagogical approach that makes explicit where metaphors break down and embrace the role of multiple complementary metaphors. Their discussion focused on explicit instructional metaphors. 
In view of the previously reported research, the goal of the present study is to identify the explicit and implicit metaphors in pedagogical texts dealing with the concept of entropy and the second law of thermodynamics. The abstract nature of this domain poses challenges for learning and thus, it is to be expected that authors of pedagogical texts will explicitly use metaphor in presentations of this topic. Moreover, the pervasive use of conceptual metaphors implicit in everyday language as well as scientific texts covering other scientific topics, as reviewed above, suggests that implicit metaphor will be pervasive here as well. Identifying these implicit metaphors in pedagogical texts is a needed first step before turning to their appropriation by learners in future research. We also examine the relationship between these implicit metaphors and explicit instructional metaphors. We seek to contribute to the debate in the science education literature regarding what instructional metaphors to select when teaching about entropy and the second law of thermodynamics. Our guiding assumption is that implicit instructional metaphors need to be appropriated by learners and that instructional metaphors are more likely to be effective if they are consistent with implicit metaphors found in pedagogical texts. We turn to a discussion of these pedagogical implications after describing the research methods employed and presenting our findings.

\section{Method}

The present study sought to identify explicit and implicit conceptual metaphors in portions of science textbooks dealing with the concept of entropy and the second law of thermodynamics. Three textbooks were selected for analysis spanning different presentations of the topic. In this section, we describe the text corpus that served as the basis for analysis as well as the analytical procedures used. We limit ourselves to qualitative analysis and reporting of findings in this study. Our justification for avoiding the reporting of frequencies of metaphors in the texts is that 
use of metaphorical construals as those addressed here are influenced by the extent to which certain topics are treated in the texts analyzed and the extent to which the treatments are mathematically sophisticated. Our empirical claims and the implications that we draw from them do not depend on precise frequencies of occurrence being reported.

\section{Textual Data Analyzed}

Three university textbooks were selected that include treatments of entropy and the second law of thermodynamics. We used three criteria for the selection of the textbooks. First, it was important that they were representative of texts to which the majority of university students studying the topic of thermodynamics are exposed since we sought to identify stable patterns of metaphorical language that are common to pedagogical discourse dealing with this topic. That is, we selected textbooks that are used widely (in Sweden and elsewhere) and we avoided texts that are idiosyncratic in some way. For example, two textbooks that were considered and then rejected were The Feynman Lectures on Physics (Feynman, Leighton, \& Sands, 1963), widely celebrated but considered idiosyncratic in style so rarely used in undergraduate teaching, and The Dynamics of Heat (Fuchs, 1996), because of its explicitly innovative treatment of entropy as a substance-like quantity. Moreover, we avoided the use of popular treatments of the topic, as in Galileo's Finger: The Ten Great Ideas of Science (Atkins, 2003). A second criterion, related to the first, was to make sure that the textbooks covered the topic at the macroscopic and microscopic levels as well as the link between both. This is related to the first criterion of representativeness since this scope constitutes mainstream pedagogical treatment of the topic. It also ensures completeness: the metaphors identified will then span all aspects of the concept of entropy and the second law of thermodynamics. Third, because we were interested in identifying entrenched patterns of metaphorical mappings that are characteristic of pedagogical discourse on 
this topic, we selected texts that spanned a range of sub-specializations and degree of sophistication. That is, we included textbooks in physics and chemistry, introductory textbooks and a more advanced, mathematical treatment. The implicit metaphors we report are only those found in all three textbooks analyzed.

Specific segments were selected from the three textbooks so as to span discussion of the concept of entropy and the second law of thermodynamics at macroscopic and microscopic levels and the link between them. The texts selected were as follows:

Sears and Zemansky's University Physics: with Modern Physics (Young \& Freedman, 2003). This is an introductory physics textbook, typically used for first year physics teaching at university. All of a single chapter, "Chapter 20: The Second Law of Thermodynamics" (pp. 754783), was selected for analysis from this textbook. Section headings were: "Directions of thermodynamic processes," "Heat Engines," "Internal-combustion Engines," "Refrigerators," "The Second Law of Thermodynamics," "The Carnot Cycle," "Entropy," and "Microscopic Interpretation of Entropy."

Chemical Principles by Zumdahl (1998) is an introduction to chemistry, aimed at first year chemistry majors. The beginning of Chapter 10 "Spontaneity, Entropy, and Free Energy" (pp. 390-412) was selected for analysis from this textbook. Section headings were: "Spontaneous Processes and Entropy," "The Isothermal Expansion and Compression of an Ideal Gas," “The Definition of Entropy," "Entropy and Physical Changes," "Entropy and the Second Law of Thermodynamics," and "The Effect of Temperature on Spontaneity."

Introductory Statistical Mechanics by Bowley and Sánchez (1999) is an introduction to statistical mechanics, typically studied at the second or third year by physics majors. Chapters 2 , "Entropy and the Second Law of Thermodynamics" (pp. 25-51), 4, "The Ideas of Statistical 
Mechanics" (pp. 67-90) and the beginning of Chapter 5 "The Canonical Ensemble" (pp. 91-97) were selected.

\section{Analytical Procedures}

The analytical approach adopted in the present study involved two phases. The first phase was the identification of instances of metaphor, both explicit and implicit, in the corpus of text compiled. In the second phase, explicit metaphors were set aside and analysis focused on the categorization of the implicitly metaphorical expressions into groups reflecting a common mapping between conceptual domains - i.e. conceptual metaphors were identified. Although there are others in the corpus, the implicit conceptual metaphors reported in this study are those where the target domain is relevant to understanding the concept of entropy and the second law of thermodynamics.

Phase one.

Identifying metaphors in the texts involved two distinct strategies. First, explicit metaphors were identified so that they can be separated from the main analysis of implicit metaphor which was the focus of this study. By explicit metaphors we mean those that were marked by the authors as metaphorical in some way. Writers can use three different kinds of markers to explicitly indicate metaphorical usage (Darian, 2003): quotation marks, italics and lexical markers such as is analogous to, think of $X$ as, just as, we can imagine $X$ as, in the same way. When writers indicate metaphors in this way we treat them as explicit. Included here are both quick metaphorical phrases brought up in a sentence and not extensively discussed, as well as metaphors discussed at some length by the author. All identified explicit metaphors in the texts examined are reported here regardless of their centrality to construing the concept of entropy and the second law of thermodynamics. 
Ascertaining whether the use of linguistic markers should be treated as marking explicitly that metaphorical language is in use is not always a clear-cut issue. In particular, highlighting with italics may be used for other purposes; it can be used to mark emphasis. Therefore, there is ambiguity in the use of italics. An example is Young and Freedman's (2003) use of italics in "All heat engines absorb heat from the source at a relatively high temperature, perform some mechanical work, and discard or reject some heat at a lower temperature" (p.756) (italics in original text). Italicizing absorb, discard and reject could be seen as explicitly marking metaphorical construal of heat as a substance and/or emphasizing the contrast between a system absorbing and discarding heat. Given that our primary focus in this study was to characterize patterns of implicit metaphor and to document pervasive usage, we adopted a conservative approach where implicit metaphor was concerned. We decided to err on the side of over interpretation of explicit usage. That is, when an instance of metaphor coincided with use of italics (as in the example just cited), we interpreted this as possibly drawing attention to the metaphorical nature of the phrase even though it was possible that the author's intention was only emphasis. In other words, this insured caution in what was treated as implicit metaphor.

Second, to identify instances of implicit metaphor we made use of the Metaphor Identification Procedure (MIP) developed by the Pragglejaz Group (2007). This procedure can be applied to any given sentence to identify any metaphorical lexical units found in it. For each lexical unit, two steps are followed. First, the meaning of the lexical unit in its context is established. Next, it is determined if there are more basic meanings (more concrete, related to bodily action, more precise and/or historically older) of the lexical units in other contexts. If a more basic meaning exists in other contexts, the analyst should "decide whether the contextual meaning contrasts with the basic meaning but can be understood in comparison with it" 
(Pragglejaz Group, p. 3). If this is the case, the lexical item is given a metaphorical interpretation. Within cognitive linguistics a common assumption is that if a word is polysemous - i.e. has many related senses - the most concrete sense, such as senses related to our experiences and interactions with physical objects, is given centrality. Consider the following two examples: Example 1: “...nature spontaneously proceeds toward the states that have the highest probability.” (Zumdahl, 1998, p. 393, emphasis added)

Candidate metaphorical lexical units: "proceeds towards"

Contextual meaning:

a. Of whole sentence: The states that characterize an aspect of nature after a spontaneous change are more probable than those that characterized it before the change.

b. Of candidate metaphorical lexical units "proceeds towards": change (of state)

Basic meaning: "Proceed towards" has a more basic meaning than change. Proceed can mean walk or go and towards refers to the direction of movement of an object. Thus, there is a more concrete, spatial meaning than the contextual meaning. Since, moving in some direction is a kind of change of state the latter is a more general, abstract meaning than the former. Therefore, "proceeds towards" is treated as metaphorical where change of state is construed as movement in some direction.

Example 2: "We must find a way to connect entropy to the macroscopic properties of matter.” (Zumdahl, 1998, p. 405, emphasis added)

Candidate metaphorical lexical unit: "connect" 
Contextual meaning:

a. Of whole sentence: It is important to be able to relate the quantitative variable entropy to macroscopic properties such as temperature and volume.

b. Of candidate metaphorical lexical unit "connect": relate

Basic meaning: Connect has the basic meaning of establishing a physical link between two or more objects. A physical link is a kind of spatial relationship that can often, but not always involve physical proximity. The entities that are being related in this sentence are quantitative variables and are not literally understood in terms of spatial location apart from the general association with a particular system under consideration. There is no literal sense in which these variables can be related spatially (either close to or far from each other) or physically linked as objects can be. Therefore, "connect" is treated as metaphorical construing the relationship between variables as physical objects that are linked to each other.

In the present study, given that the objective was to identify patterns in implicit metaphorical language in large segments of text, the MIP was not applied exhaustively for every lexical unit in the corpus. Instead, the texts were read by the four researchers and candidate sentences that seemed to have metaphorical units were intuitively selected. Once selected, the MIP steps of characterizing contextual meanings and considering possible more basic meanings were carried out. As acknowledged by the Pragglejaz Group, there is a subjective element in every assessment of an individual lexical unit. Prepositions are brought up as particularly problematic and different analysts may come to different conclusions with regards to their metaphoric character. However, the procedure does provide for a systematic basis for identifying 
sources of disagreement among researchers. Therefore, particular instances can be subject to public scrutiny without relying solely on the intuitions of individual researchers, as typically has occurred in conceptual metaphor research to date (see also Semino, 2008 for discussion).

\section{Phase two.}

Once a large corpus of implicit metaphorical expressions was identified the second phase of analysis involved an iterative process of categorization. This analysis was applied to the implicit metaphorical expressions alone. In this phase, the goal was to identify systematic conceptual mappings between conceptual domains reflecting patterns in the metaphorical expressions identified. Conceptual mappings previously identified in the cognitive linguistics and science education research literature were drawn on as a starting point. Conceptual mappings not known from previous literature were described and given a category name. The researchers reached consensus regarding the final list of conceptual metaphor categories through discussion. The conceptual metaphors were then organized and reported in terms of whether they were relevant to a macroscopic level of description of entropy and the second law of thermodynamics, the microscopic level or the link between the two. The conceptual metaphors reported are those that were common to all three texts analyzed and so can be interpreted as stable features of pedagogical discourse in this domain.

\section{Results}

The findings of the study will be organized into three broad sub-sections. First, we present all the explicit metaphors that were found in the three texts analyzed. Second, we present the implicit conceptual metaphors identified - i.e. those reflected in metaphorical language that was not marked as metaphorical in the texts. Only those implicit metaphors relevant to construal of the 
concept of entropy and the second law of thermodynamics are reported. Third, we compare the conceptual mappings reflected in the explicit and implicit metaphors. This last subsection paves the way for a more extensive discussion of the implications of patterns of implicit metaphor for the selection of explicit instructional metaphors.

\section{Explicit Metaphorical Construals}

We begin with a presentation of explicit metaphors identified in the texts. Recall that by explicit we mean instances of metaphor that the author has marked as metaphorical through the use of quotation marks, italics or explicit verbal markers such as as, like, can be thought of as, can be seen as. Moreover, recall that our use of the term metaphor is broad (following Gentner and Jeziorski, 1993): we include under the term any case of understanding an idea in terms of another. This can involve superficial attribute-based judgments of similarity or mapping of relations from one domain to another. In addition, under the term metaphor we include cases where a word or phrase is used metaphorically without extended discussion of the comparison or mapping intended by the usage and cases in which such an extended discussion of mapping between domains is presented. A summary of the explicit metaphors identified in the texts is

presented in Table 1. The metaphors are grouped in the table reflecting some patterning among some of them, either because they draw on the same source domain (e.g. a substance-like construal) or because the same source and target are mapped onto each other (e.g. thermodynamics processes are construed as the movement of an object along a path). The presentation to follow is organized in terms of these patterns. 
Table 1 - Summary of explicit metaphors used in the three texts

Metaphorical Examples $^{1}$

\title{
Construal
}

\begin{tabular}{ll}
\hline Entropy As Disorder & In qualitative terms, entropy can be viewed as a measure of \\
& randomness or disorder. (Zumdahl, 1998, p. 392)
\end{tabular}

We say that the system is "disordered" ... (Young \& Freedman, 2003, p. 780)

...the universe becomes more random or "run down" (Young \& Freedman, 2003 p. 779)

\begin{tabular}{ll}
\hline Process Variables Heat & In fact, we might say that in the surroundings "work has been \\
and Work As & changed to heat." (Zumdahl, 1998, p. 404)
\end{tabular}

Substances

\begin{abstract}
All heat engines absorb heat from the source at a relatively high temperature, perform some mechanical work, and discard or reject some heat at a lower temperature (Young \& Freedman, 2003, p. 756)
\end{abstract}

The amount of heat... is proportional to the width of the incoming "pipeline" at the top of the diagram. (Young \& Freedman, 2003, p. 757)

... in this case a lot of heat can be "pumped" from the lower to the

\footnotetext{
${ }^{1}$ Italics, quotes or bold type in these examples appear as in the original text.
} 
higher temperature with only a little expenditure of work. (Young \& Freedman, 2003, p. 770)

Thermodynamic

Processes As Movement of an Object

Along a Path
Thermodynamics offers no clue as to why there should be an arrow of time, but indicates that entropy is an increasing function of time (Bowley \& Sánchez, 1999, p. 44)

We can think of a refrigerator as a heat engine operating in reverse. (Young \& Freedman, 2003, p. 761)

[A heat pump] functions like a refrigerator turned inside out. (Young \& Freedman, 2003, p. 763)

Such a "free compression" would be the reverse of the free expansion... (Young \& Freedman, 2003, p. 782)

\section{Energy Exchange As A Suppose that you have \$50 to give away. Giving to a millionaire}

Financial Transaction will not create much of an impression. However, to poor college student, $\$ 50$ represents a significant sum and will be received with considerable joy. The same principle can be applied to energy transfer via the flow of heat ... (Zumdahl, 1998, p. 410) 


\author{
A Theory Is A Building ...to quote Henri Poincaré: "Science is built up of facts as a house \\ is built up of stones; but an accumulation of facts is no more \\ science than a heap of stones is a house.” (Bowley \& Sánchez, \\ 1999, p. 27) \\ $\mathrm{Z}$ acts as a bridge connecting the microscopic energy stated of the \\ system to the free energy... (Bowley \& Sánchez, 1999, p. 97)




\section{Entropy As Disorder.}

The first explicit metaphorical mapping identified in the texts involves understanding entropy in terms of the notion of disorder. In this metaphor, the state of a thermodynamic system consisting of both the configuration of elements of the system and their energies is understood as a collection of objects organized with some degree of order. Entropy is seen as providing some measure of this disorder, with greater entropy construed as greater disorder and vice versa. According to the second law of thermodynamics, spontaneous processes must involve an increase in entropy and so are construed in the metaphor as involving greater disorder.

As mentioned in the introduction, construing entropy metaphorically in terms of disorder is common in the teaching of thermodynamics. This metaphorical construal was found to be explicitly used in Zumdahl (1998) and Young \& Freedman (2003). In both texts, explicit metaphorical statements indicating that entropy can be understood as disorder were made and then followed by elaborated examples, such as a messy room and a shuffled deck of cards. In contrast, in their statistical mechanics treatment of entropy, Bowley and Sánchez (1999) make no use of this metaphor.

Process Variables As Substances.

In its qualitative, literal sense heat is the process of transfer of the energy of motion of particles. This process of transfer of energy was construed as a substance-like entity that changes location, a construal that was explicitly marked as metaphorical in the analyzed texts. In addition, work is defined as the product of a force and the distance over which the force acts. Literally, a system can perform work and an outcome of the process is that the energy of motion of the particles of the surroundings increases. Explicit use of metaphor was found in which the link between work performed and its outcome is construed as one substance (work) transformed into another (heat). 
Zumdahl (1998) and Young \& Freedman (2003) made use of explicit substance-like metaphorical construals of the process variables heat and work That is, work was construed as a substance-like entity that can change form in "work has been changed into heat"; heat engines are said to "absorb," "discard" or "reject" heat; heat is said to be "pumped;" and arrows on a diagram representing thermodynamic processes producing heat is said to be a "pipeline." No such explicit construal can be found in Bowley and Sánchez (1999). Moreover, there was no explicit metaphorical construal of entropy as substance-like in the text although there were some implicit metaphorical construals (described later).

Thermodynamic Processes As Movement Along A Path.

Literally a thermodynamic process involves coordinated changes in the states of different parts of a thermodynamic system and/or its surroundings. The temperature of one part of a system can drop as that of another rises, the volume of the system can increase and a coordinated increase in the energy of motion of the particles of surroundings occurs. Explicit metaphorical construal of these processes as the movement of an object along a path was found in the texts. In this metaphorical mapping, the changing system is construed as an object and the change is construed as movement along a path.

All three texts include examples of explicitly metaphorical construals where a thermodynamic process is construed as movement of an object along a path. We find reference to “speed" used to construe the rate of a process in Zumdahl (1998, p. 391). Bowley and Sánchez (1999), use a classical poetic metaphor for the concept of entropy when they refer to it as the "arrow of time," construing processes of change as movement along a path and entropy as an arrow pointing in some direction along that path. Young and Freedman (2003) indicate that some thermodynamic processes can be viewed as some processes run in reverse or seen from the 
“inside out." That is, a refrigerator can be thought of as a heat engine run "in reverse," free compression can be seen as free expansion run "in reverse" and a heat pump is like a refrigerator "turned inside out." Since "reverse" and "inside out" have basic spatial senses, these metaphors can be seen as additional examples of construing thermodynamics processes metaphorically as movements along a path.

Other explicit metaphors.

There were three explicitly metaphorical expressions that did not fit into any pattern. All three appeared in Young and Freedman (2003): the respiration reaction was construed as "burning;, the high concentration of gasoline was construed as "rich;" and the path through which the fluid of a refrigerator passes was construed as a "circuit."

The texts included two metaphors that are presented through extended discussions. Zumdahl (1998) invites the reader to view a thermodynamic system and its interaction with the surroundings as resembling financial transactions, a metaphor we refer to as Energy Exchange As A Financial Transaction. Counterparts in the two domains are explicitly mapped out in this metaphor:

\section{Energy Is Money}

Entropy Is the Satisfaction Experienced When Receiving Money

Temperature Is the Degree of Wealth of the Recipient.

In this metaphor, the small entropy change of a system associated with receipt of energy at high temperature is seen as corresponding to the lesser satisfaction experienced by someone receiving a sum of money when they are already very wealthy.

Another metaphor mapped out more extensively is the comparison of theories and their constituent ideas to a building or other types of construction. Bowley and Sánchez (1999, p. 27) 
quote Henri Poincaré as saying: "Science is built up of facts as a house is built up of stones; but an accumulation of facts is no more science than a heap of stones is a house." This metaphor is used when introducing the facts that ground the second law of thermodynamics. A related metaphor is the construal of a theoretical construct as a physical construction as in " $\mathrm{Z}$ acts as a bridge connecting the microscopic energy state of the system to the free energy ..." (Bowley \& Sánchez, 1999, p. 97).

The main goal of this study was to identify metaphorical mappings implicit in pedagogical texts dealing with entropy and the second law of thermodynamics and then to examine how these implicit mappings relate to explicit metaphors used in the texts analyzed in this study and discussed in the literature as potentially valuable instructional metaphors. Having surveyed the explicit metaphors used in the analyzed texts we turn to presenting the implicit mappings identified.

\section{Implicit Metaphorical Construals}

We report the conceptual metaphors inferred as patterns of mappings between conceptual domains reflected in implicit metaphorical language identified in the texts. The presentation of conceptual metaphors is organized in terms of three broad aspects of the domain covered by the concept of entropy and the second law of thermodynamics: the macroscopic level of description; the microscopic level; and the relationship between the levels. The full set of conceptual metaphors identified as common to all three texts and illustrative quotes from the corpus are presented in Table 2. For each conceptual metaphor one full sentence quoted from the corpus is presented in the table with full citation information. Within each of the three aspects of the domain, we organize the presentation of conceptual metaphors in clusters of related mappings where relevant. With each cluster, we describe the mappings between source and target domains 
and then summarize the linguistic evidence for that cluster, pointing out single words and short phrases that reflect the mapping inferred. While we use quotation marks to indicate that these were actually found in the texts analyzed we avoid use of full citations to make the prose more readable.

Table 2 - Summary of common conceptual metaphors used to construe entropy and the second law of thermodynamics

\section{Aspect of Conceptual Metaphors $\quad$ Examples $^{2}$}

\section{Domain}

\begin{tabular}{|c|c|c|}
\hline Macro & Location event structure & \\
\hline level & metaphor and elaborations & \\
\hline & States of a system are & Provided the water is pure, and the three phases \\
\hline & locations & are present in thermodynamic equilibrium ... \\
\hline & & (Bowley \& Sánchez, 1999, p. 34) \\
\hline & Changes in a system are & When the process goes from state $1\left(\mathrm{P}_{1}, \mathrm{~V}_{1}\right)$ to \\
\hline & movements along a path & state $2\left(\mathrm{P}_{1} / 4,4 \mathrm{~V}_{1}\right)$ with no mass on the pan ... \\
\hline & & (Zumdahl, 1998, p. 398) \\
\hline & Caused changes to a & The driving force for a spontaneous process is an \\
\hline & system are forced & increase in the entropy of the universe. \\
\hline & movements & (Zumdahl, 1998, p. 392) \\
\hline
\end{tabular}

\footnotetext{
${ }^{2}$ Italics are added in these quoted examples to highlight the metaphorical components of the sentences.
} 
Spontaneous change is

directed movement

Agentive (sometimes

sentient) goal-directed

movement
The natural progression of things is from order

to disorder, from lower entropy to higher

entropy. (Zumdahl, 1998, p. 392)

When two systems are placed in thermal contact

with each other they tend, if left to themselves, to

come to equilibrium with each other. (Bowley \&

Sánchez, 1999, p. 27)

The second law of thermodynamics...

determines the preferred direction for such

processes. (Young \& Freedman, 2003, p 755)

Since $\mathrm{n}$ and $\mathrm{T}$ are held constant in this

experiment ... (Zumdahl, 1998, p. 401)

An example of such a forbidden process would

law/principle/equation is be if all of the air in your room spontaneously

a social law

moved to one half of the room... (Young \&

Freedman, 2003, p. 782)

\section{Object event structure}

metaphor and elaborations

Entropy is a possession _...then every substance has a positive entropy

which at $\mathrm{T}=0$ may become zero. (Bowley \&

Sánchez, 1999, p. 40) 
Entropy as part/whole The total entropy is the sum of the entropies of the two systems. (Bowley \& Sánchez, 1999, p. 69)

\begin{tabular}{ll}
\hline Change of energetic state of & ...the energy it gives up is transferred to the \\
system is loss of energy from & surroundings. Some of this energy is transferred \\
system (as heat) & as heat. (Zumdahl, 1998, p. 410)
\end{tabular}

\begin{tabular}{|c|c|}
\hline A mathematical function is a & Our new expression for the entropy gives \\
\hline machine & $P=\frac{N k_{B} T}{V}($ Bowley \& Sánchez, 1999, p. 70) \\
\hline
\end{tabular}

Correlation is The entropy change associated with the mixing accompaniment of two pure substances is expected to be positive. (Zumdahl, 1998, p. 396)

\begin{tabular}{l} 
Micro Location event structure \\
Level metaphor \\
$\begin{array}{ll}\text { Microstates are locations } & \text { Entropy is a thermodynamic function that } \\
\text { describes the number of arrangements (positions } \\
\text { and/or energy levels) available to a system } \\
\text { existing in a given state. (Zumdahl, 1998, p. } \\
\text { Change of microstate is } & \text { 396) } \\
\text { movement into/out of a } & \ldots \text { the molecules go into solution independently } \\
\text { location } & \text { of each other. (Bowley \& Sánchez, 1999, p. 70) }\end{array}$ \\
\hline
\end{tabular}




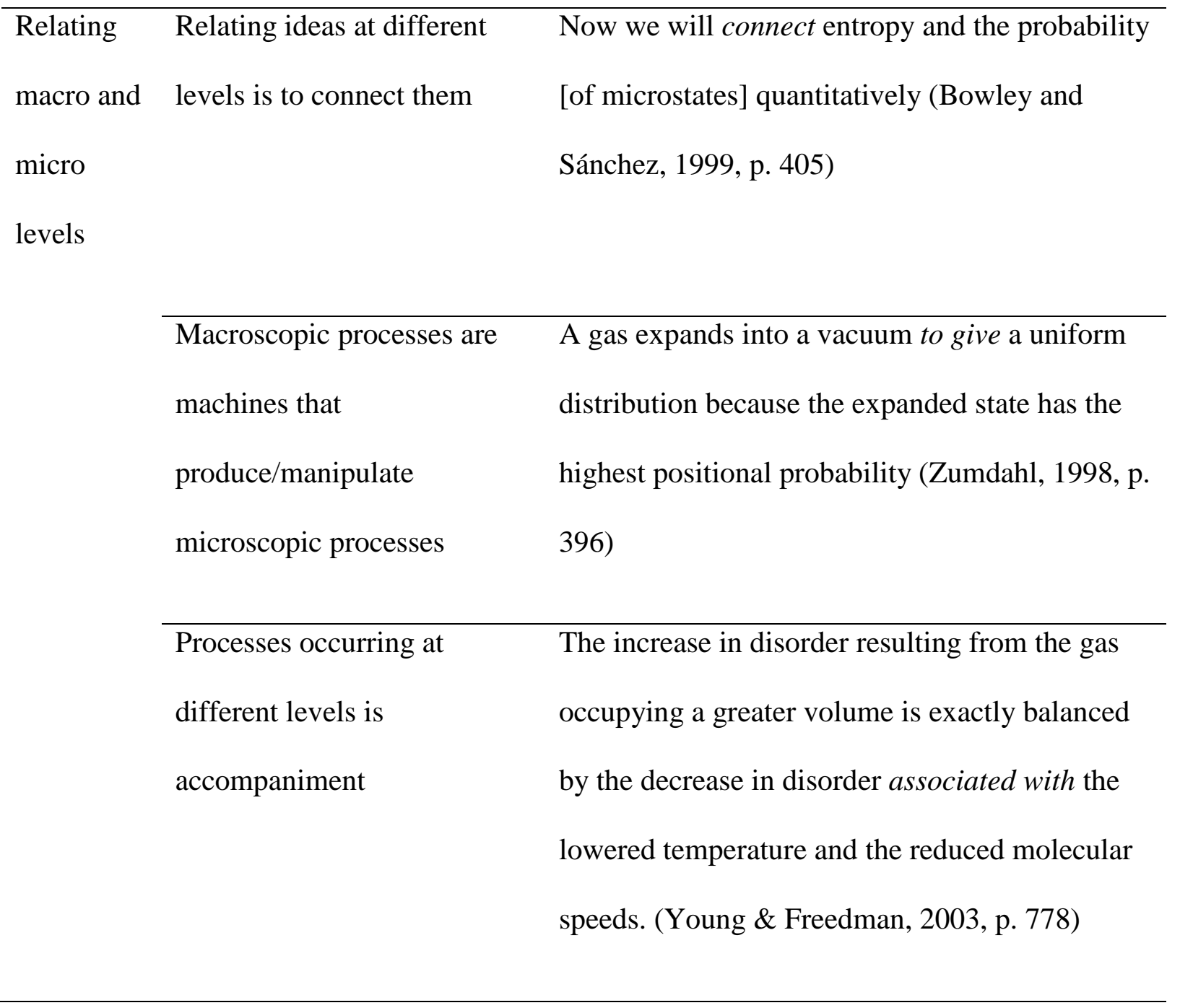

\section{Conceptual metaphors used at the macroscopic level.}

\section{Use and elaborations of the Location Event Structure metaphor.}

We begin by reporting the use of a related cluster of conceptual metaphors that amount to the application to thermodynamics of the generic Location Event Structure metaphor described by Lakoff and Johnson (1999). In the analysis reported here, we found that this conceptual metaphor is applied directly to a thermodynamic system. The mappings can be summarized as follows: 
States of a System Are Locations

Changes in a System Are Movements Along A Path

Caused Changes to a System Are Forced Movements

We follow Lakoff and Johnson's $(1980,1999)$ convention of presenting conceptual metaphors in the form of A Is B, where A refers to the abstract target domain and B to the concrete source domain. We present clusters of mappings together because they can be viewed as the same extended target domain mapped onto the same extended source domain. Overall, we can say that the mappings cohere. If the state of a system is construed as a location in which the system can be placed, this coheres with the construal of a change of state as movement of an object from one location to another along a path. Moreover, caused changes are understood as the forced movement of an object from one location to another.

For example, we find reference to a thermodynamic system being "in" equilibrium or solid state, or "at" some pressure or temperature. A change that a system undergoes is construed as movement of an object from one location to another as in the "process goes from state 1 ... to state 2 ..." or references to the "pathway between reactants and products." Moreover, caused changes are construed as forced movements as in statements like "The driving force for a spontaneous process is an increase in the entropy of the universe."

This set of mappings amounts to the application of the generic Location Event Structure metaphor to thermodynamics. Other patterns of metaphorical expressions were found to cohere with these mappings but involved further elaboration of the target and source domains. In thermodynamics, a distinction is made between processes that are spontaneous and those that are not. As mentioned in the introduction, the second law of thermodynamics describes the nature of spontaneous changes, and entropy is a concept that provides a quantitative formulation of such 
changes. Various elaborations of the Location Event Structure metaphor were identified. While changes generally are construed as movements from one location to another, spontaneous changes are construed as movements along specific paths, or towards particular destinations. Moreover, the spontaneity of change is captured by construing thermodynamic systems as entities capable of self-generated or agentive movement, and in some cases involving sentience where the entity prefers particular paths. Finally, thermodynamic changes are subject to the constraints of particular experimental set ups and general laws and principles. This is captured through the construal of a thermodynamics system/agentive entity as subject to physical obstacles or social laws. These latter construals implicate the kind of force dynamics construals discussed by Talmy $(1988,2000)$. These can be seen as variants of the sub-mappings of the Location Event Structure metaphor described by Lakoff and Johnson (1999, p. 178): Difficulties Are Impediments To Motion; Freedom Of Action Is The Lack of Impediments To Motion. Therefore, we add the following mappings:

Spontaneous Change of A System Is Directed Movement A System Is An Agentive (Sometimes Sentient) Entity Experimental Conditions Are Physical Obstacles A Scientific Law/Principle/Equation Is A Social Law Thus, we find reference to the "direction" of some process, that natural processes occur in "one way", or that they "proceed" or "evolve toward" particular states. The states toward which a system naturally proceeds are characterized in terms of an overall increase in entropy. The system can be attributed a certain degree of agency, or goal directedness, as when systems in contact are referred to as tending "if left to themselves, to come to equilibrium." Moreover, a further attribution of sentience to this goal-directed entity is reflected in viewing a system as 
"wanting" a particular outcome or "preferring" one outcome over another. Conditions such as constant temperature or pressure can be construed as potentially moving objects that have been held back or blocked by some force. We find reference to "keeping" a system close to equilibrium or temperature "held" constant. Finally, scientific laws, principles and equations are construed as social laws that govern the movement of this sentient entity. Thus, we find that certain changes/movements are "allowed" or "prohibited" or they can be construed as "violating" a law or equation.

\section{Use and elaboration of the Object Event Structure metaphor.}

While the metaphors identified so far reflect application and elaboration of the Location Event Structure metaphor, the next cluster of metaphors to be considered here make use of the Object Event Structure metaphor (Lakoff \& Johnson, 1999), which also is a common construal in everyday language. Recall that this involves a subtle figure-ground shift with respect to the Location Event Structure metaphor. In parallel to the Location Event Structure metaphor, the generic Object Event Structure metaphor involves states/attributes being construed as objects/possessions, changes construed as transfer of possession, and caused changes construed as forced transfer of possessions. The application of this generic cluster of mappings was much more limited in texts analyzed in this study. The application was limited to the concepts of entropy and change of energetic state as target concepts. Moreover, not all sub-mappings of the cluster were used. That is, the following mappings were identified:

Entropy Is A Possession

Entropy Is A Part/Whole

Change of Energetic State is Loss of Energy From the System (As Heat) 
First in this cluster is the construal of entropy as a substance-like possession. However, there were no metaphorical construals of change in entropy or caused change in entropy so the use of the Object Event Structure metaphor to construe entropy was limited. However, since the concept of entropy is the tool with which the directionality of change in thermodynamic systems is quantified, generic metaphorical resources for construing numerical quantities are to be expected. The Arithmetic Is Object Construction metaphor (see Lakoff \& Núñez, 2000) is relevant here. In what can be understood as an elaboration of the construal of entropy as an object/possession, we found entropy construed in terms of parts and wholes. Finally, the generic change of state is transfer of a possession was applied to the construal of changes in energetic state. Here, change in energetic state is construed as loss of energy as heat. The focus in this study is on the concept of entropy and the second law of thermodynamics not the concept of energy per se. We include this last mapping here because change in energetic state involving the release of heat is a feature of spontaneous processes, the focus of the second law.

Therefore, we find that a system or a component of it is said to "have" entropy. We also see references to "the entropy of a system." In all three texts analyzed, entropy as a numerical quantity was construed as a whole object ("total entropy") to which parts, smaller quantities of entropy, can "contribute." Such part/whole construals of entropy are part of the accounting of how much entropy a system or component of it "has." Moreover, the metaphorical construal of change in energetic state as loss of energy as a possession (as heat) was found in references to energy being “given up" and energy as "waste.” Accompanying expressions reflecting this metaphor are terms like "reservoir" and "heat sink" which invite a construal of the surroundings as essentially an infinite container. This construal supports understanding the change in the energetic state of the system as loss of useful energy. 


\section{A Function Is A Machine.}

The metaphor A Function Is A Machine was described by Lakoff and Núñez (1997) (see also Vergnaud, 1996). This metaphor includes the following submappings:

A Function Is A Machine

The Domain of a Function Is A Collection of Input Objects

The Range of a Function Is A Collection of Output Objects

In the analyzed texts, this generic mathematical metaphor is applied in thermodynamics as it would be applied wherever mathematical functions are implicated. For example, we find expressions for entropy and calculations based on those expressions "giving", "generating" and "producing" other mathematical expressions or quantities.

\section{Correlation Is Accompaniment.}

Thermodynamic systems and processes are characterized in terms of a variety of variables and coordinated changes in these variables. An important aspect of understanding these systems and processes is to describe relationships between these variables and to relate particular quantitative variables to particular qualitative features of a physical system or process. Formulating accounts of these relationships in literal terms can lead to laborious sentences of great complexity. Metaphor is often used to simplify such accounts. We refer to a systematic metaphorical mapping identified in the texts analyzed as Correlation Is Accompaniment. In this metaphor two correlated variables or a variable correlated with a qualitative physical process are construed as two entities accompanying one another.

Naming this conceptual metaphor Correlation Is Accompaniment is inspired by Lakoff \& Johnson's (1999, p. 218) Causation Is Correlation metaphor but we think what is going on here is somewhat different. Lakoff and Johnson state as a typical example "Homelessness came with 
Reaganomics." According to Lakoff \& Johnson, in this example, two independent entities or processes that are somehow causally related are construed as correlated ${ }^{3}$. Instead, in the mapping we are calling Correlation Is Accompaniment, we are dealing with different quantities that describe aspects of the same process or relate quantitative and qualitative levels of description or different representations of some property. For example, the process of heating involves a change in the variable entropy but it is not appropriate to speak of two independent processes that are somehow causally related. Thus, in the texts analyzed we suggest that expressions like "the entropy change associated with the mixing of two pure substances" (Zumdahl, 1998, p. 396) are best considered as reflecting the mapping Correlation Is Accompaniment.

\section{Conceptual metaphors used at the microscopic level.}

The only conceptual metaphors identified at the microscopic level were direct applications of the Location Event Structure metaphor to the microscopic level of description of thermodynamic systems. That is, we identified the mappings:

\section{Microstates Are Locations}

\section{Change of Microstate Is Movement Into/Out Of A Location}

For example, systems are said to "be in" or "occupy" a microscopic state, such states are said to be "accessible" to the system and "molecules" are said to "go into solution."

In contrast to the frequent use of the Location Event Structure metaphor, the Object Event Structure metaphor was not used at the microscopic level treatment of the analyzed texts. Indeed, Young and Freedman (2003, p. 779) explicitly argue against such a construal. They write: "Unlike energy, however, entropy is not something that belongs to each individual particle

\footnotetext{
${ }^{3}$ It might be argued that the concrete nature of the source domain as reflected in "came with" might be captured more accurately by calling the metaphor Causation Is Accompaniment.
} 
or pair of particles in the system. Rather, entropy is a measure of the disorder of the system as a whole" (Young \& Freedman, 2003, p. 779).

\section{Conceptual metaphors used to relate macroscopic and microscopic levels.}

One central characteristic of the concept of entropy is that it provides a way to relate microscopic phenomena to perceivable or measurable macroscopic properties. The microscopic theory of statistical mechanics is considered to be an important foundation for explaining the second law of thermodynamics. A number of conceptual metaphors were identified as playing a role in relating the macro and micro levels of description of thermodynamic systems:

Relating Ideas At Different Levels Is To Connect Them

Macroscopic Processes Are Machines That Produce/Manipulate Microscopic Processes.

Correlation Is Accompaniment (applied across levels)

Evidence for the first of these, Relating Ideas At Different Levels Is To Connect Them, can be found in reference to quantities or properties of systems at different levels being "connected" to each other; or when disorder is seen as the "underpinning" of a definition of entropy. This conceptual metaphor reflects the more generic conceptual metaphors Ideas Are Objects as well as Theories Are Buildings, identified by Lakoff and Johnson (1980, 1999). One can think of relating ideas being required to construct a theory or theoretical understanding. A theory/building cannot be constructed unless the ideas/objects that make it up are connected. The use of "underpinning" above reflects the notion of connecting implicated in using objects to construct a large structure, and can be seen as an instance of treating the microscopic level as a foundation for understanding macroscopic processes and processes. Indeed Bowley and Sánchez (1999, p. 67) ask "What is the microscopic basis of the entropy?" Also, a physical implication of connecting is to bring things close enough to each other to be connected or at least to orient them 
in the appropriate way. Thus, we find reference to ideas that may seem to be unrelated as being "far removed." That is, the difficulty of understanding the relationship between ideas at different levels is construed as objects separated by a large distance. By "bringing them into line," we align these two concepts at different levels vertically, so that we can see the connection or in trying to show that they are related we need to "bring them into line."

The second conceptual metaphor relating levels is Macroscopic Processes Are Machines That Produce/Manipulate Microscopic Processes. This can be seen as an application of the Caused Changes Are Forced Movements sub-mapping of the Location Event Structure metaphor (Lakoff \& Johnson, 1999). Lakoff and Johnson mention examples like "The runner threw the crowd into a frenzy" and "The changing exchange rate sent the economy into chaos." In the analyzed texts, we found that a macroscopic process causing change at the microscopic level is construed as manipulating, forcing movement or generating a product at the microscopic level, as in the case of "A gas expands into a vacuum to give a uniform distribution because the expanded state has the highest positional probability" (Zumdahl, 1998, p. 396).

A third conceptual metaphor in this group is the application of Correlation Is Accompaniment to correlation of processes across levels. For example, we find references to decrease in disorder being "associated with" or "accompanying” lowered temperature.

\section{Comparison of Explicit and Implicit Metaphors}

In this subsection, we turn to an analysis of the similarities and differences between the metaphors marked explicitly as metaphorical and those that are left implicit in the texts analyzed. Similarities are addressed first followed by differences.

Two degrees of similarities can be noted. Strong similarity involves the same target domain being mapped onto the same source domain. A weaker form of similarity is when the 
same source domain is used but mapped onto different target domains. The explicit and implicit application of the Location Event Structure metaphor is an example of strong similarity. As shown above, there was extensive implicit use of the Location Event Structure metaphor and elaborations of it when construing thermodynamics states, changes of state, caused change of state, the conditions under which these changes occur and the laws that characterize them. Similarly, explicit metaphorical construals of changes of thermodynamic states using this same Location Event Structure mapping - namely, changes of state were construed as movements along a path. That is, only one of the submappings of the Location Event Structure metaphor was marked explicitly in the texts analyzed.

A weaker degree of similarity can be found in the use of a substance-like construal as a source domain in explicit and implicit metaphors but in each case involving different target domains. The explicit metaphor was used to construe the target concepts work and heat as substances; entropy was construed as a substance/possession only implicitly.

As for differences, other explicit metaphors did not have any implicit counterparts. That is, Entropy As Disorder, A Theory Is A Building and Energy Exchange Is A Financial Transaction were used explicitly but neither the full mapping between source and target or use of the source domains was identified in the implicit metaphors found in the text. However, one further connection between the two sets of metaphors is worthy of mention. The Energy Exchange As Financial Transaction include the submappings Energy Is Money, Entropy Is Satisfaction Experienced When Receiving Money and Temperature Is Degree of Wealth of the Recipient. This explicit metaphor is interesting to consider in connection with the implicit metaphor Change In Energetic State Is Energy Loss (as Heat). While these metaphors differ in the details of the mapping between source and target and differ in the specific source domain 
used, they do have some similarities. First, both metaphors treat energy as an entity exchanged; that is, an implicit construal of energy as substance is shared by both. Second, there is an implicit notion of the value of energy present in both. According to the first law of thermodynamics there is no such thing as energy loss, only exchange. Metaphorical references to the loss of energy as heat to the surroundings appeal to the idea that the energy is no longer in a useful form. That is, both the explicit and implicit metaphors use the notion of value when conceptualizing energy exchange although the mappings between source and target and the specific source domains do differ in both cases.

\section{Discussion}

To summarize, we have identified a few explicitly marked metaphors in the analyzed texts and extensive patterns in implicit metaphorical language that reflect a range of underlying conceptual metaphors common to three educational texts on the subject of entropy and the second law of thermodynamics. The largest set of conceptual metaphors was identified at the macroscopic level. Many could be seen as either sub-mappings of the Location Event Structure metaphor or elaborations of it. In addition, there was some limited use of the Object Event Structure metaphor to conceptualize entropy at the macroscopic level. Moreover, entropy was construed in terms of a part/whole schema. In addition, despite the first law of thermodynamics formulation of energy as a conserved quantity, in the context of the second law (incorporating the idea of energy degradation) energy is construed as a possession that can be "lost." The generic conceptual metaphor A Mathematical Function Is A Machine was found, as expected, to be common in the texts we analyzed. Finally, correlated variables and processes were conceptualized as entities accompanying one another. The only conceptual metaphor used in all texts at the microscopic level was the Location Event Structure metaphor used to construe microstates as locations. As 
for the relationship between levels, we identified a handful of metaphors: Ideas at different levels were construed as objects connected to one another; macroscopic processes were construed as machines that produce or manipulate microscopic entities or processes; and variable and processes occurring at different levels were construed as entities accompanying one another. The differences identified in this study in the use of implicit metaphors at the two levels of description are consistent with the findings reported in Haglund et al. (2010) on the different senses of entropy - i.e. that the macroscopic, thermodynamic sense and microscopic statistical sense are distinct but related senses of the word with distinct underlying concepts. We have also analyzed the similarities and difference between the explicit and implicit metaphors found in the texts.

As has been done with other aspects of scientific discourse that have been characterized (e.g. Duschl \& Osborne, 2002; Halliday and Martin, 1993; Lemke, 1990; Yerrick \& Roth, 2005) further research is now needed to examine how metaphors found implicit in pedagogical discourse in this domain are appropriated and how this appropriation can be supported in instruction. Specifically, the fact that learners are exposed to both implicit and explicit use of metaphor with both similarities and differences suggests both a positive contribution of metaphor to the learning process and potential learning challenges. Research into both the positive contributions and learning challenges is needed. But even before such research is carried out, we argue that our findings do have implications for instruction. We base this argument on two assumptions. First, pervasive patterns of implicit metaphors will need to be appropriated by learners because they cannot be eliminated from pedagogical discourse; they are entrenched and not subject to the language user's (e.g. textbook writer's) conscious reflection and control. Second, we assume that consistency between explicit instructional metaphors and implicit 
metaphorical mappings would make both easier to learn. In light of these two assumptions, we discuss the implications of our findings for using explicit metaphors in instruction. We suggest that the findings can be used to argue for the value of some instructional metaphors over others and for the general instructional strategy of using multiple analogies. A third, more controversial, assumption that the phenomenon of metaphor is a deep one implicating the representation of scientific concepts not just pedagogical language is also discussed. We consider the implications of this assumption for teaching and learning science.

\section{Selecting Instructional Metaphors and Conceptual Metaphor: Disorder, Paths, Freedom, and Money}

As noted in the introduction, there is a debate in the science education literature addressing the adequacy of various instructional metaphors for teaching the concept of entropy and the second law of thermodynamics (e.g. Brissaud, 2005; Falk et al., 1983; Lambert, 2002; Leff, 1996, 2007; Styer, 2000). In the present study, we found a number of metaphors used explicitly as metaphors by the authors of the texts analyzed that are directly relevant to teaching the concept of entropy and the second law of thermodynamics: increasing entropy was construed as increasing disorder; thermodynamics processes were construed as objects moving along a path; and energy exchange was construed as a financial transaction. Lambert (2002), Styer (2000) and Leff (2007) all argue that the disorder metaphor, misleads students. Accepting the value of metaphor as a teaching tool in general, Styer (2000) considers the metaphor Entropy is Disorder to be vague, imprecisely defined, and emotionally charged. Above all, he notes that disorder does not capture the important points that entropy relates to a class of many microstates, not individual microstates and is an extensive quantity. As an alternative, Styer proposes the use of the metaphor Entropy is Freedom. Although he acknowledges similar problems associated with the vagueness of the idea and its emotional connotations, he suggests that the freedom to choose between several 
microstates is a powerful notion that can support understanding of the concept of entropy. The metaphor Entropy is Freedom was not utilized as an explicit instructional metaphor in the three analyzed texts. The issue we address here is how the implicit metaphors identified in our analysis can be drawn on to evaluate the promise of candidate instructional metaphors.

We begin by assuming that pervasive patterns of implicit metaphorical language in a domain need to be appropriated by a learner and that consistency between an explicit, instructional metaphor and implicit metaphorical patterns in discourse is a reason to evaluate the instructional metaphor positively. The explicit metaphorical construal of thermodynamic processes as objects moving along a path is a direct application of the Location Event Structure metaphor used implicitly with great frequency. Thus, using consistency with implicit metaphor as the criteria for evaluation makes this explicit metaphor unproblematic. Evaluating the explicit instructional metaphors Entropy is Disorder and Entropy is Freedom is less straightforward.

It was pointed out in the results sections that there was no similarity at the level of full mapping or similarity of source domains between the explicit Entropy As Disorder metaphor and any implicit metaphors identified. Closer scrutiny of this metaphor is needed so that it may be evaluated alongside Entropy Is Freedom. The notion of disorder, in its most concrete sense, has to do with the degree of pattern or organization in the locations of components of a system. Therefore, it may seem to be consistent with the Location Event Structure metaphor applied to thermodynamic systems in which thermodynamic states are construed as locations, changes as movements etc. Examples used to illustrate the idea that thermodynamic systems tend to greater disorder often highlight changes in patterns in the locations of components of a system, as in "the mixing of colored ink and water starts from a state of relative order (low entropy)..." (Young \& Freedman, 2003, p. 779) referring to changes in the relative locations of the particles of ink and 
water. However, close scrutiny of the two metaphors reveals some subtle but important differences. When the notion of disorder is used to construe the relative absence of pattern in the locations of components of a system in the example above the locations are literal properties of the components not a metaphorical construal. However, in this same example when we say that as the ink mixes in with the water it is undergoing a change "from" some state, the spatial term is used metaphorically. That is, any given configuration of the components of the system is construed as a given location of the system in a metaphorical state space. The spatial nature of the notion of disorder does become metaphorical when the idea is applied beyond the configuration of locations of the components of a system to encompass, more broadly, the notion of energetic states. But even when it is applied more broadly in this way, the use of disorder does not align neatly with the Location Event Structure metaphor. The Location Event Structure metaphor construes a given state of the system as a whole as a single location in phase space. In contrast, the disorder metaphor applied to energetic states maps the multiple energetic states of the components to multiple locations and collectively these are then construed as ordered or disordered.

In light of this analysis, we conclude that the use of a spatial source domain to construe changes in a thermodynamics system is different in the Entropy is Disorder metaphor and the application of the Location Event Structure metaphor to thermodynamics. We suggest that this lack of alignment points to a potential inadequacy with the disorder metaphor. Indeed, the reader may have found the extension of the construal of disorder to an energetic state more generally difficult to make sense of in the last paragraph. We share this discomfort. Indeed it may well be that the view that the disorder metaphor is vague and poorly defined derives from the difficulty of aligning the notion with a closely related implicit conceptual metaphor that is pervasively used 
in this domain. Moreover, the ease with which a class of states can be conceptualized as multiple locations in the Location Event Structure metaphor contrast markedly with the difficulty of making sense of classes of states through the notion of disorder. We noted in the results section that Bowley and Sánchez (1999) chose not to use the disorder metaphor in their text on statistical mechanics. It may be that the disorder metaphor is a cul-de-sac, rather than a useful stepping stone towards a more advanced conceptualization of entropy.

In contrast, the explicit instructional metaphor Entropy is Freedom is consistent with several of the conceptual metaphors identified in the texts, namely the Location Event Structure metaphor and various elaborations of it. We have seen that in the latter metaphor states of a system are construed as locations and the changing system is construed as an entity that moves from one location to another. Moreover, spontaneous change is construed as movement in particular directions, often elaborated as agentive goal-directed movement with the agent sometimes further elaborated as a sentient entity desiring or preferring particular directions. High entropy is construed in relation to this cluster of metaphors as a desired destination. In addition, physical laws are construed as social laws that govern the actions of a sentient entity.

When we view the instructional metaphor of Entropy as Freedom against the background of this cluster of conceptual metaphors we find considerable overlap. More freedom as a description of the outcome of the spontaneous process seems to incorporate all of the above conceptual metaphors within it. Freedom is desired by a sentient, goal directed entity; it is associated with the existence of multiple locations where an entity could be or move to; moreover, it is not limited to a configurational interpretation, for freedom of movement also implicates confinement in possible energetic states more generally, not only location. Freedom also fits well with a construal of physical laws as social laws. Indeed, in their analysis of this 
metaphor, Jeppsson et al. (2011) point out that freedom suggests liberty to "move about" at random without restrictions or external influence and note that it incorporates the notion of human endeavor, as a basis for understanding natural laws. Thus, the freedom metaphor fares well in this evaluation of consistency with a cluster of implicit metaphors. Indeed, in his popular introduction to the concept of entropy Atkins explains: "A gas, with its freely flying molecules, is more disordered than a liquid, and a gas has a higher entropy than the liquid from which it evaporates" (Atkins, 2003, p. 121). Atkins uses "freely" fleetingly and not in the context of an explicit development of the freedom metaphor (indeed disorder was the metaphor explicitly developed). This suggests that the notion of freedom is easily motivated by the implicit conceptual metaphors commonly used in pedagogical discourse in the domain. In sum, the Entropy is Freedom metaphor incorporates many of the conceptual metaphors we identified suggesting that it is likely to be a very promising instructional metaphor.

We turn next to the explicit metaphor Energy Exchange Is A Financial Transaction. We pointed out in the results section that this explicit metaphor shares elements with implicit metaphor Change In Energetic State Is Loss of Energy (As Heat). They share the basic construal of energy as a substance-like entity and their inclusion of the notion of energy having some value. Crucially, where the target and source domains overlap the mappings in both cases cohere; that is, in both cases energy is construed as a substance with some value. However, the Energy Exchange Is A Financial Transaction includes a number of other important submappings and incorporates two other important target concepts: temperature and entropy. ${ }^{4}$ Together this

\footnotetext{
${ }^{4}$ Analogies between thermodynamics and economics have been drawn and elaborated upon elsewhere, both in order to explain thermodynamics (e.g. Nordholm, 1997) and to explain economics (e.g. Saslow, 1999). In contrast to Zumdahl (1998), Nordholm and Saslow note that finding a counterpart for temperature is problematic. For instance,
} 
explicit metaphor helps clarify relationships between the concepts energy, entropy and temperature in a way that goes well beyond the implicit metaphor of Change In Energetic State Is Loss of Energy (As Heat). Therefore, based on the criterion of consistency with implicit metaphor the Energy Exchange Is A Financial Transaction fares well. Its value, however, seems to lie in mappings that go beyond the related implicit metaphor. In contrast, the Freedom metaphor was found to be consistent with a cluster of implicit metaphors, and its value seemed to be primarily in capturing in one vivid concept a vast collection of implicit metaphorical mappings.

In sum, we conclude that in addition to explicit versions of the Locations Event Structure metaphor both the Freedom and Financial Transaction metaphors are consistent with implicit metaphors found to be pervasive across the texts analyzed and so seem promising as instructional metaphors. In contrast, the disorder metaphor does not fare well based on this consistency criterion.

\section{Conceptual Metaphor and the Multiple Instructional Metaphor Strategy}

In this section, we discuss the variety in implicit conceptual metaphors identified in our analysis highlighting how different construals can be adopted of the same target concept. We suggest that this variety implies that multiple instructional metaphors are preferable to single metaphors as others have also argued (e.g. Aubusson et al., 2006; Duit, 1991; Spiro et al., 1989).

In the Location Event Structure metaphor and its cluster of elaborations applied to thermodynamics, entropy is a property that characterizes the state of the system construed as a

wealth (as used by Zumdahl) fails to bring across the intensive character of temperature. Instead Nordlund proposes "standard of living" and Saslow suggests "level of economic development". 
location. Moreover, in this metaphor the changes of state are construed as an object that moves from one location to another. However, an alternative construal of entropy and the system that it characterizes was found in our analysis, one that involves a figure-ground reversal when compared to the Location Event Structure metaphor. This alternative makes use of the Object Event Structure metaphor where entropy is construed as a possession of the system, and sometimes elaborated as a substance-like entity contained in the system. Moreover, in our analysis we found entropy construed in terms of a part/whole schema which we also reflects the substance-like construal of entropy associated with the Object Event Structure metaphor. This construal is used to emphasize the additive, extensive character of entropy, closely associated with quantitative treatments of the concept. In other research, entropy has been found to be more frequently construed in terms the Object Event Structure metaphor in the context of quantitative problem-solving (Jeppsson et al., submitted).

In the science education literature there are two diametrically opposed positions with regard to the pedagogical value of the substance-like construal of entropy. On the one hand, it forms the heart of the Karlsruhe Physics approach to teaching thermodynamics (Falk et al., 1983). In this approach, entropy assumes the role of being the central extensive variable in thermodynamics and is deliberately conceptualized as an object that is transferred during changes of state. Entropy is introduced as a fluid-like substance or identified with the everyday conception of heat. Within Karlsruhe Physics, Herrmann (2004) proposes introducing a substance-like construal of entropy in the following way: "The higher the temperature of an object, the more entropy is contained in it. The greater the mass of an object, the more entropy is contained in it" (p. 38). Here the state function entropy is construed as a physical object located 
inside a container - i.e. in our terms the proposal is to explicitly and consistently use the Object Event Structure metaphor.

In contrast, there is a repeatedly voiced view among science educators and researchers in science education that if you use "correct" language then students are more likely to learn correctly. Although not discussing the concept of entropy specifically, Brookes (2006) suggests that conceptual metaphors in science texts often lead to misconceptions when interpreted in an overly literal fashion by students and recommends that teachers and textbook writers should "try to use language that is [as] consistent as possible with the lexical ontology of the model." (pp. 176-177). This line of argument applied to entropy would lead to the conclusion to expunge substance-like language when dealing with the concept given that this would be an incorrect ontological classification.

From a perspective that acknowledges the presence of a variety of conceptual metaphors used to construe a concept, the Karlsruhe Physics approach can be seen as involving an overly restrictive use of a single metaphor. As noted in the introduction, Christensen et al. (2009) found that a common belief among many students is that entropy is conserved which may lead to difficulties in understanding the role of entropy in the second law of thermodynamics. We think that this misunderstanding is likely to be reinforced by the Karlsruhe approach through the exclusive use of a single metaphor. On the other hand, the suggestion to expunge problematic metaphor from pedagogical language is an overly restrictive and impractical recommendation for teaching given that, as our findings suggest, a feature of pedagogical discourse in this domain is the flexible use of a diverse set of conceptual metaphors that need to be appropriated by students.

One resolution of this dilemma is to accept the reality of variation in implicit metaphor in pedagogical discourse and assume that all metaphors will need to be appropriated by learners. 
This is the case for the concept of entropy discussed here and many other abstract concepts. A related issue in the science education literature is the extent to which any given scientific concept that we want students to learn can be classified within a single, stable ontology (Gupta, Hammer \& Redish, 2010; Slotta, 2011). Some have argued that scientists themselves draw flexibly on distinct ontological construals of a concept suggesting that teaching that assumes a single stable ontology may mischaracterize the learning problem (Gupta et al., 2010). As noted by Gupta et al. (2010), the flexible use of conceptual metaphor in scientific texts is consistent with a dynamic ontology view.

In the previous subsection, we argued that explicit instructional metaphors can be evaluated based on their consistency with patterns of implicit metaphor used in pedagogical discourse. The variation in the construal of a scientific concept through the use of multiple implicit metaphors has implications for the range of explicit instructional metaphors that are likely to be needed. If explicit instructional metaphors are to be selected in part in order to ease the appropriation of implicit metaphors, the former must be selected to span the range of construals found in the latter. This discussion implies that an instructional strategy that relies on multiple explicit instructional analogies is more appropriate than attempts to find the best metaphor, or an optimal combination of a small number of complementary metaphors. Our findings here and previous research (Jeppsson, et al., submitted) suggest that one aspect of learning in this conceptual domain is to learn the subtle conditions of use of multiple conceptual metaphors, each guiding construal of some aspect of the domain (see Amin, 2009, for a similar discussion of the attempts to treat energy as a substance-like entity for instructional purposes). Our proposal is consistent with the suggestion made initially by Spiro, et al (1989), and others since (see Aubusson et al., 2006) to use multiple complementary metaphors. This argument 
applies to teaching the concept of entropy and the second law of thermodynamics addressed in this paper and teaching any domain of science in which the use of implicit metaphor is found to be an important feature of pedagogical discourse.

\section{How Deep is the Phenomenon of Metaphor?}

We end this discussion by addressing a more foundational issue: the depth of the phenomenon of metaphor. While this study did not present a quantitative analysis of frequencies of the metaphors identified for reasons presented earlier, the use of implicit metaphor was pervasive in the texts. The Location Event Structure metaphor was especially widespread; so much so, that it is often difficult to think of ways of paraphrasing such metaphorical uses so as to avoid metaphor. Moreover, explicit, and colorful metaphors used often align neatly with implicit conceptual metaphors. Our discussion of the instructional metaphor Entropy Is Freedom above illustrated this point. Recall also the use of the particularly poetic phrase referring to entropy as “an arrow of time” in Bowley and Sánchez (1999). A parallel example can be found given in Atkins (2003) (not analyzed in this study) in his popular treatment construing entropy as a "signpost" indicating the direction in which the system must proceed. All these colorful metaphors are consistent with the construal of spontaneous change as directed movement identified as implicit in the texts analyzed. Moreover, seeing states as locations underlies the use of graphs, such as PV-graphs, representing the relationship between the pressure and volume of a system, where each point in the graph corresponds to a state of the system. All this raises the question of the depth of the phenomenon of metaphor.

While this was not highlighted in the introduction, Lakoff and Johnson $(1980,1999)$ have suggested that conceptual metaphor is a fundamental cognitive phenomenon, in which the understanding of abstract concepts are grounded in experience-based knowledge gestalts. An 
important question that arises is the cognitive status of conceptual metaphors like the Location Event Structure metaphor when they are used to construe thermodynamic systems as found in the texts analyzed. Given that these are pedagogical texts, one might assume that such metaphorical language is used solely for pedagogical purposes. The implication of that assumption would be that literal paraphrases are possible. Alternatively, if Lakoff and Johnson are correct, it could be that this metaphorical language reflects a deeper cognitive phenomenon in which thermodynamic states are construed by scientists metaphorically.

The second alternative gains some theoretical and empirical plausibility. Theoretically, that metaphor can be constitutive of scientific theories is a position accepted by some philosophers (Boyd, 1979/1993; Giere, 1988; Hesse, 1966). Empirically a number of investigations comparing the use of metaphor in scientific and pedagogical texts dealing with the same topic have found some consistency between the use of metaphors in both contexts (Knudsen, 2003; Semino, 2008). In this work, the same source domains were found to be mapped onto the same target domains in both scientific journal articles and explicitly instructional texts intended for a general audience. The consistency of source domains across scientific and pedagogical contexts could imply that the source domains are playing an important role in the representation of the concepts involved not simply supporting communication. Some research examining scientific reasoning from a conceptual metaphor perspective (Brown, 2003; Fernandez-Duque \& Johnson, 1999, 2002; Jeppsson et al. submitted) is consistent with this conclusion. The extent to which metaphor is a fundamental cognitive phenomenon that grounds understanding of abstract scientific concepts needs to be further examined and its pedagogical significance explored. 
This view that abstract scientific concepts might be represented in terms of concrete, experience-based source domains shares a great deal with research on cognition and learning that adopts the embodiment assumption (Clark, 1997; diSessa, 1993, Greeno, 1989; Sherin, 2001). From this perspective, understanding and reasoning with abstract concepts are seen as ultimately grounded in sensorimotor experience. It has been argued that abstract scientific understanding and reasoning and the use of algebraic equations in physics problem-solving make use of intuitive knowledge resources such as phenomenological primitives (diSessa, 1993) and the conceptual schemata of symbolic forms (Sherin, 2001), both of which derive from sensorimotor experiences. Learning science from this perspective involves the recruitment and organized application of these intuitive knowledge structures in a way sanctioned by science. If the phenomenon of conceptual metaphor is as deep as Lakoff and Johnson $(1980,1999)$ have suggested, then the source domains of conceptual metaphors may turn out to be another kind of intuitive knowledge resource grounding abstract scientific understanding and reasoning (see Jeppsson et al., submitted for some preliminary evidence for this view). Moreover, how these conceptual metaphors are appropriated will then need to be understood. The exposure to, and attempts to understand, pedagogical texts infused with implicit conceptual metaphor of the kinds described in this paper may be part of the appropriation story. This view is supported by the more general claim in developmental psychology that much of cognitive development can be seen as the appropriation of conceptualizations implicit in discourse (Tomasello, 1999). In addition, Amin (2009) has suggested that learning research needs to be conducted from a discourse analytic perspective focusing on conceptual metaphors as cites of meaning negotiation. A great deal of research into these issues is needed if the depth and significance of the phenomenon of conceptual metaphor for the teaching and learning of science is to be understood. 
In conclusion, our findings indicate that implicit metaphorical construals are extensive and systematic in pedagogical texts dealing with entropy and the second law of thermodynamics. The appropriation of these metaphors by learners needs to be researched. Assuming that this aspect of pedagogical discourse needs to be appropriated by learners, we suggested that identifying these implicit metaphors can help evaluate candidate explicit instructional metaphors and implies that the use of multiple metaphors is a preferred instructional strategy. The cognitive depth of the phenomenon of metaphor is suggested by a variety of lines of research. Further work to characterize the status of metaphor in scientific understanding is needed and its pedagogical significance explored.

\section{References}

Al-Zahrani, A. (2008). Darwin's metaphors revisited: Conceptual metaphors, conceptual blends, and idealized cognitive models in the theory of evolution. Metaphor and Symbol, 23(1), $50-82$.

Amin, T. G. (2009). Conceptual metaphor meets conceptual change. Human Development, 52(3), 165-197.

Atkins, P. (2003). Galileo's finger: The ten great ideas of science. Oxford, UK: Oxford University Press.

Aubusson, P. J., Harrison, A. G., \& Richie, S. M. (2006). Metaphor and analogy in science education. Dordrecht, The Netherlands: Springer.

Baierlein, R. (1994). Entropy and the second law: A pedagogical alternative. American Journal of Physics, 62(1), 15-26.

Bowley, R., \& Sánchez, M. (1999). Introductory statistical mechanics (2 ${ }^{\text {nd }}$ Ed.). Oxford: Clarendon Press. 
Boyd, R. (1979/1993). Metaphor and theory change: What is "metaphor" a metaphor for? In A. Ortony (Ed.), Metaphor and thought, $2^{\text {nd }}$ edition, (pp. 481-432). Cambridge, UK: Cambridge University Press.

Brissaud, J.-B. (2005). The meanings of entropy. Entropy, 7(1), 68-96.

Brookes, D. T. (2006). The role of language in learning physics. Unpublished Doctoral Thesis. Rutgers, The State University of New Jersey. New Brunswick, NJ.

Brookes, D. T., \& Etkina, E. (2007). Using conceptual metaphor and functional grammar to explore how language used in physics affects student learning. Physical Review Special Topics - Physics Education Research, 3(010105), 1-16.

Brosseau, C., \& Viard, J. (1992). Quelques réflexions sur le concept d'entropie issues d'un enseignement de thermodynamique. Enseñanza de las ciencias, 10(1), 13-16.

Brown, T. L. (2003). Making truth: Metaphor in science. Chicago, IL: University of Illinois Press.

Carey, S. (1999). Sources of conceptual change. In E. K. Schlonick, K. Nelson, S. A. Gelman \& P. H. Miller (Eds.), Conceptual development: Piaget's legacy, (pp.293-326). Mahwah, NJ: Erlbaum.

Carey, S. (2009). The origin of concepts. Oxford, UK: Oxford University Press.

Christensen, W. M., Melzer, D. E., \& Ogilvie, C. A. (2009). Student ideas regarding entropy and the second law of thermodynamics in an introductory physics course. American Journal of Physics, 77(10), 907-917.

Clark, A. (1997). Being there: Putting brain, body, and world together again . Cambridge, MA: MIT Press. 
Clement, J. (2009). Creative model construction in scientists and students: The role imagery, analogy, and mental simulation. Dordrecht, The Netherlands: Springer.

Cochran, M. J., \& Heron, P. R. L. (2006). Development and assessment of research-based tutorials on heat engines and the second law of thermodynamics. American Journal of Physics, 74(8), 734-741.

Dagher, Z. R. (1994). Does the use of analogies contribute to conceptual change? Science Education, 78(6), 601-614.

Darian, S. (2003). Understanding the language of science. Austin, TX: University of Texas Press diSessa, A. A. (1993). Towards an epistemology of physics. Cognition and Instruction, $10(2$ \& 3), 105-225.

Duit, R. (1991). On the role of analogies and metaphors in learning science. Science Education, 75(6), 649-672.

Duschl, R.A., and Osborne, J. (2002). Supporting and promoting argumentation discourse in science education. Studies in Science Education, 38(1), 39-72.

Duschl, R. A., Schweingruber, H. A., Shouse, A. W. (2007). Taking science to school. Washington, DC: The National Academies Press.

Evans, V. (2005). The meaning of time: polysemy, the lexicon and conceptual structure. Journal of Linguistics, 41(1), 33-75.

Falk, G., Herrmann, F., \& Schmid, G. B. (1983). Energy forms or energy carriers. American Journal of Physics, 51(12), 1074-1077.

Fernandez-Duque, D., \& Johnson, M. L. (1999). Attention metaphors: How metaphors guide the cognitive psychology of attention. Cognitive Science, 21(1), 83-116. 
Fernandez-Duque, D., \& Johnson, M. L. (2002). Cause and effect theories of attention: The role of conceptual metaphors. Review of General Psychology, 6(2), 153-165.

Feynman, R. P., Leighton, R. B., \& Sands, M. (1963). The Feynman lectures on physics. Vol. 13. Reading, UK: Addison-Wesley.

Fuchs, H. U. (1996). The dynamics of heat. New York, NY: Springer.

Gentner, D. \& Jeziorski, M. (1993). The shift from metaphor to analogy in Western science. In A. Ortony (Ed.), Metaphor and thought, $2^{\text {nd }}$ edition, (pp. 447-480). Cambridge, UK: Cambridge University Press.

Gentner, D. \& Wolff, P. (2000). Metaphor and knowledge change. In E. Dietrich \& A. Markman (Eds.), Cognitive dynamics: Conceptual change in humans and machines (pp. 295-342). Mahwah, NJ: Lawrence Erlbaum Associates.

Gibbs, R. W. (1994). The poetics of mind: Figurative thought, language, and understanding. Cambridge, UK: Cambridge University Press.

Gibbs, R. W. (2005). Embodiment and cognitive science. Cambridge, UK: Cambridge University Press.

Giere, R. N. (1988). Explaining science: A cognitive approach. Chicago, IL: Chicago University Press.

Greeno, J. G. 1989. Situations, mental models, and generative knowledge. In D. Klahr and K. Kotovsky (Eds.), Complex information processing, (pp. 285-318). Hillsdale, NJ: Lawrence Erlbaum.

Gupta, A., Hammer, D., \& Redish, E. F. (2010). The case for dynamic models of learners' ontologies in physics. Journal of the Learning Sciences, 19(3), 285-321. 
Haglund, J., Jeppsson, F. \& Strömdahl, H. (2010). Different senses of entropy: Implications for education. Entropy, 12(3), 490-515

Halliday, M. A. K. \& Martin, J. (1993). Writing science: Literacy and discursive power. Pittsburgh, PA: University of Pittsburgh Press.

Herrmann, F. (2004). Entropy from the beginning. Paper presented at the GIREP, Ostrava.

Hesse, M. B. (1966). Models and analogies in science. Notre Dame, IN: University of Notre Dame Press.

Jeppsson, F., Haglund, J., Amin, T. G. \& Strömdahl, H. (submitted). Exploring the use of conceptual metaphors in solving problems on entropy.

Jeppsson, F., Haglund, J. Strömdahl, H. (2011). Exploiting language in teaching of entropy. Journal of Baltic Science Education, 10(1), 27-35.

Kautz, C. H., Heron, P. R. L., Shaffer, P. S., \& McDermott, L. C. (2005). Student understanding of the ideal gas law, Part II: A microscopic perspective. American Journal of Physics, 73(11), 1064-1071.

Knudsen, S. (2003). Scientific metaphors going public. Journal of Pragmatics, 35(8), $1247-$ 1263.

Lakoff, G. \& Johnson, M. (1980). Metaphors we live by. Chicago, IL: Chicago University Press.

Lakoff, G. \& Johnson, M. (1999). Philosophy in the flesh. New York, NY: Basic Books.

Lakoff, G., \& Núñez, R. E. (1997). The metaphoric structure of mathematics: Sketching out cognitive foundations for a mind-based mathematics. In L. D. English (Ed.), Mathematical reasoning: Analogies, metaphors, and images (pp. 21-89). Mahwah, NJ: Lawrence Erlbaum Associates Publishers. 
Lakoff, G., \& Núñez, R. E. (2000). Where mathematics comes from: How the embodied mind brings mathematics into being. New York, NY: Basic Books.

Lakoff, G., \& Turner, M. (1989). More than cool reason: A field guide to poetic metaphor. Chicago, IL: University of Chicago Press.

Lambert, F. L. (2002). Disorder - A cracked crutch for supporting entropy discussions. Journal of Chemical Education, 79(2), 187-192.

Leff, H. S. (1996). Thermodynamic entropy: The spreading and sharing of entropy. American Journal of Physics, 64(10), 1261-1271.

Leff, H. S. (2007). Entropy, its language and interpretation. Foundations of Physics, 37(12), 1744-1766.

Lemke, J. L. (1990). Talking science: Language, learning and values. Norwood, NJ: Ablex. Nersessian, N. J. (2008). Creating scientific concepts. Cambridge, MA: MIT Press.

Nordholm, S. (1997). In defense of thermodynamics - an animate analogy. Journal of Chemical Education, 74(3), 273.

Pragglejaz Group (2010). MIP: A method for identifying metaphorically used words in discourse. Metaphor and Symbol, 22(1), 1-39.

Reddy, M. J. (1979). The conduit metaphor - A case of frame conflict in our language about language. In A. Ortony (Ed.), Metaphor and thought (pp. 284-324). New York, NY: Cambridge University Press.

Reif, F. (1999). Thermal physics in the introductory physics course: Why and how to teach it from a unified atomic perspective. American Journal of Physics, 67(12), 1051-1062.

Saslow, W. M. (1999). An economic analogy to thermodynamics. American Journal of Physics, 67(12), 1239-1247. 
Semino, E. (2008). Metaphor in discourse. Cambridge, UK: Cambridge University Press.

Sherin, B. L. (2001). How students understand physics equations. Cognition and Instruction, 19(4), 479-541.

Slotta, J. D. (2011). In defense of Chi's ontological incompatibility hypothesis. The Journal of the Learning Sciences, 20(1), 151-162.

Spiro, R. J., Feltovitch, P. J., Coulson, R. L., \& Anderson, D. K. (1989). Multiple analogies for complex concepts: Antidotes for analogy-induced misconception in advanced knowledge acquisition. In Vosniadou, S. \& Ortony, A. (Eds.), Similarity and analogical reasoning. (pp. 498-531). New York, NY: Cambridge University Press.

Styer, D. F. (2000). Insight into entropy. American Journal of Physics, 68(12), 1090-1096.

Talmy, L. (1988). Force dynamics in language and cognition. Cognitive Science, 12(1), 49-100.

Talmy, L. (2000). Toward a cognitive semantics. Vol. 1, Concept structuring systems. Cambridge, MA: MIT Press.

Tomasello, M. (1999). The cultural origins of human cognition. Cambridge, MA: Harvard University Press.

Vergnaud, G. (1996). The Theory of Conceptual Fields. In L. P. Steffe, P. Nesher, P. Cobb, G. A. Goldin, \& B. Greer (Eds.), Theories of Mathematical Learning (pp. 219-239). Mahwah, NJ: Lawrence Erlbaum Associates.

Vosniadou, S. \& Ortony, A. (1989), Similarity and analogical reasoning. New York, NY: Cambridge University Press.

Yerrick, R. K. \& Roth, W-M. (2005). Establishing scientific classroom discourse communities: Multiple voices of teaching and learning research. Mahwah, NJ: Lawrence Erlbaum Associates. 
Young, H. D. \& Freedman, R. A. (2003). Sears and Zemansky's university physics: with modern physics. (11 $1^{\text {th }}$ Ed.). San Francisco, CA: Pearson Education.

Zumdahl, S. S. (1998). Chemical principles ( $3^{r d}$ Ed.). Boston, MA: Houghton Mifflin. 